\title{
Changes in Body Temperature and Sleep-Wakefulness after Intrapreoptic Injection of Methoxamine in Rats
}

\author{
Ra. Vetrivelan, Hruda Nanda Mallick and Velayudhan Mohan Kumar \\ Department of Physiology, All India Institute of Medical Sciences \\ New Delhi, India. Pin: 110029.
}

\section{SUMMARY}

Several pieces of evidence suggest that the noradrenergic afferents in the medial preoptic area produce sleep and hypothermia by acting on $\alpha_{1}$ adrenergic receptors. On the other hand, in a few studies monitoring body temperature with a rectal probe, preoptic injection of the $\alpha_{1}$ adrenergic agonist methoxamine produced contradictory changes in body temperature and sleep-wakefulness. Such contradictions call for the re-examination of methoxamine induced body temperature changes using a better technique like telemetric recording. In the present study, we monitored body temperature and sleep-wakefulness simultaneously after the micro-injection of $0.5,1$, and $2 \mu \mathrm{mol}$ methoxamine, into the medial preoptic area of adult male Wistar rats. Methoxamine injection produced hypothermia but no major change in sleep-wakefulness during the 3 hours after drug injection, except for a short period $(15 \mathrm{~min})$ of sleep after 120 min of injection. A short period of wakefulness, coinciding with the maximum fall in body temperature ( $30 \mathrm{~min}$ after injection) occurred when methoxamine was administered at higher doses. The results of this study indicate that $\alpha_{1}$ adrenergic receptors participate in preoptically mediated thermoregulatory measures

Reprint requests to: Dr. H.N. Mallick, Department of Physiology, All India Institute of Medical Sciences, New Delhi, India; e-mail: hmallick@hotmail.com that reduce body temperature. Hypothermia induced by methoxamine might have masked the hypnogenic action of this drug.

\section{KEYWORDS}

medial preoptic area, telemetry, dose response, hypothermia, $\alpha_{1}$ adrenoceptors, norepinephrine

\section{INTRODUCTION}

Several studies have indicated the importance of the medial preoptic area (mPOA) in the regulation of body temperature $\left(\mathrm{T}_{\mathrm{b}}\right)$ and sleep-wakefulness (SW) (Nauta, 1946; McGinty \& Sterman, 1968; Boulant, 1980; Asala et al., 1990; John \& Kumar, 1998). Local warming of the preoptic area (POA), results in panting and sweating, whereas lesion of this area results in the elevation of $T_{b}$. (Magoun et al., 1938; Anderson et al., 1965). The importance of the mPOA in thermoregulation was shown by a study in which the destruction of the neurons of this area in rats, by local injection of NMDA, produced a long-lasting hyperthermia and an increase in the range of thermostat setting (Kumar \& Khan, 1998). On the basis of transection studies, Nauta (1946) showed the importance of the POA for 'the capacity of sleeping' in rats. Later studies showed that the selective destruction of mPOA neurons produces a long-lasting insomnia with marked reduction in the deeper stages of sleep, including rapid eye move- 
ment (REM) sleep. The reduction in the duration of sleep episodes in the lesioned rats indicates the role of the mPOA in sleep maintenance (John et al, 1994; John \& Kumar, 1998).

The mPOA has a rich noradrenergic innervation (Anden et al., 1966; Palkovits et al., 1974; Swanson \& Hartman, 1975), and such fibers have been implicated in the regulation of $\mathrm{T}_{\mathrm{b}}$ and $\mathrm{S}-\mathrm{W}$ (Panskepp et al., 1973; Kumar et al., 1993, Ramesh \& Kumar, 2000; Kumar, 2003b). Iontophoretically applied norepinephrine (NE) causes alterations in the firing rates of sleep-active and waking-active neurons of the POA (Osaka \& Matsumura 1994, 1995). Thermosensitive neurons of the preoptic area are sensitive to the microelectrophoretic application of NE (Hori \& Nakayama 1973; Hori et al., 1982), and their in vitro activity is modulated by NE (Sun et al., 1997). Moreover, histological studies showed a moderate level of $\alpha_{2}$ adrenergic receptors, a diffuse distribution of $\alpha_{1}$ receptors, and a low density of $\beta$ receptors in the POA (Palacios \& Wamsley, 1983; Unnerstall et al., 1984; Nicholas et al., 1993; Scheinin et al., 1994).

Norepinephrine, when injected into the POA, induces hypothermia (Feldberg and Myers, 1965; Poole \& Stephenson, 1979; Datta et al., 1985; Mallick et al., 1988). The results of studies using alpha and beta blockers indicate the possibility that this hypothermic response is mediated through $\alpha$ adrenergic receptors (Datta et al., 1985, 1988). As the $\alpha_{2}$ agonist clonidine did not produce any change in $T_{b}$, the authors suggested that the hypothermic response is mediated through $\alpha_{1}$ adrenergic receptors (Ramesh \& Kumar, 1998). No change was observed in rectal temperature when 5-50 $\mu \mathrm{g}$ of methoxamine, an $\alpha_{1}$ agonist, was injected in the anterior hypothalamic, preoptic area of cats (Myers et al., 1987) or when $1 \mu \mathrm{g} / \mu \mathrm{L}$ of the same drug was microdialyzed into the POA of guinea pigs at the rate of $2 \mu \mathrm{L} / \mathrm{min}$ for $3 \mathrm{~h}$ (Quan et al., 1992). On the other hand, the administration of $2 \mu \mathrm{g}$ methoxamine into the mPOA of rats produced a fall in $T_{b}$ (Mallick \& Alam, 1992). In all these studies, rectal temperature was recorded by inserting probes into the colon. Dose dependent changes in $T_{b}$, measured by telemetric technique after methoxamine injection into the $\mathrm{mPOA}$ in rats, have not been reported to date.

Local injection of NE into the mPOA of rats induces arousal (Hernandez-Peon \& Chavez-Ibara 1963; Mohan Kumar et al., 1984; Kumar et al., 1993). The arousal effect produced by the local application of NE was shown to be due to its action on presynaptic $\alpha_{2}$ adrenergic receptors (Ramesh et al., 1995). Kumar and coworkers (Kumar et al., 1993; Ramesh \& Kumar 1998) suggested that the normal postsynaptic action of $\mathrm{NE}$ at the level of the POA was to induce sleep and that it might be mediated by postsynaptic $\alpha_{1}$ adrenergic receptors. On the other hand, local injection of $2 \mu \mathrm{g}$ methoxamine induces increased wakefulness (Mallick \& Alam, 1992). Such contradictions in prior reports call for the reexamination of the findings using better techniques, and a dose-response study to find the changes in $T_{b}$ and $S-W$ produced by the stimulation of the $\alpha_{1}$ adrenergic receptors of the mPOA.

The induced fall in $T_{b}$ does produce arousal (Kent \& Satinoff, 1990). The injection of drugs into the POA can also produce changes in $T_{b}$ and $\mathrm{S}-\mathrm{W}$, which are not interdependent (Datta et al., 1987; Ticho \& Radulovacki, 1991). So, it is important to monitor the changes in $T_{b}$ and $S-W$ simultaneously to correlate the changes in these parameters.

\section{EXPERIMENTAL PROCEDURES}

Twenty male adult Wistar rats (obtained from Experimental Animal Facility, All India Institute of Medical Sciences, New Delhi, India) weighing 
between 180 and $220 \mathrm{~g}$ were kept in the animal house for at least 4 weeks before the surgical procedure, with ad libitum access to food and water and a $14 \mathrm{~h} / 10 \mathrm{~h}$ light/dark cycle (lights on at 06:00 h). The animal house temperature was maintained at $26 \pm 1^{\circ} \mathrm{C}$.

$T_{b}$ was recorded telemetrically, using a radio transmitter TA10TAF-40 (Data Sciences International, USA). Under pentobarbitone sodium (Aldrich Thomas Co., USA) anesthesia (40 mg/kg body weight, i.p.), a small longitudinal midline incision $(1.5 \mathrm{~cm})$ was made on the abdomen. The transmitter was gently pushed into the abdominal cavity, and the area of incision was sutured. Rats were also chronically implanted with electrodes for recording the electrooculogram (EOG), electroencephalogram (EEG), and electromyogram
(EMG) to assess S-W (Kumar et al., 1984). Bilateral guide cannulae for the injection of drugs, aimed at $2 \mathrm{~mm}$ above the $\mathrm{mPOA}$, as per the De Groot (1959) atlas, were also implanted, as described before (Kumar et al., 1984; Datta et al., 1985) (see Fig. 1 for injection site).

Experiments were carried out in a soundattenuated chamber maintained at $26 \pm 1{ }^{\circ} \mathrm{C}$. The animals were introduced into the chamber with the plugged cables at least 1 day before the experiment and left undisturbed. The experimental procedure included continuous telemetric recording of intraperitoneal temperature (DATA QUEST $1.1^{\circledR}$, Data Sciences International, USA) and digital recording of EOG, EEG, and EMG (BSL PRO $36^{\circledR}$, BIOPAC Systems Inc, USA) for $2 \mathrm{~h}$ before and for $3 \mathrm{~h}$ after the intra-cerebral injection.

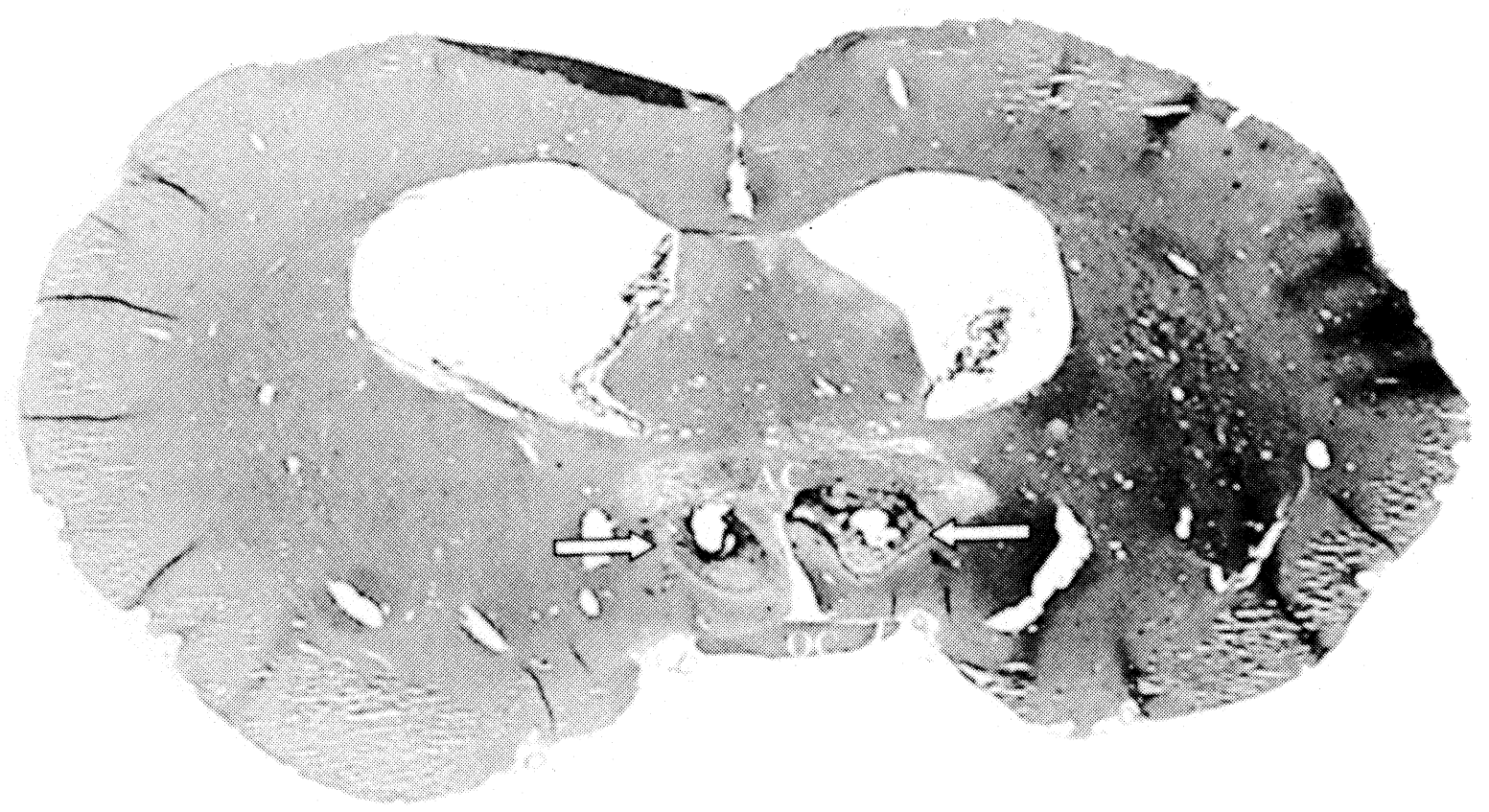

Fig 1: Photomicrograph of rat brain section at the level of mPOA, showing the injection site by horizontal arrows. AG Anterior commissure; OC- Optic chiasm. Scale bar - $1 \mathrm{~mm}$ 
Temperature signals from the transmitters, picked up by the receiver (RPC-1) placed in the recording chamber, were fed into a computer through the Data Exchange Matrix (Data Sciences International, USA). The EOG, EEG, and EMG signals (sampling rate $500 \mathrm{samples} / \mathrm{sec}$ ) were fed into a MP-30 unit (BIOPAC Systems Inc, USA) and recorded in another computer. The recordings started at 10:00 h and were terminated at 15:10 h. Recordings were discontinued from 12:00 to 12:10 $\mathrm{h}$, during which period injections were given.

The animals were divided into four groups. The data of only five animals from each group receiving injections into the $\mathrm{mPOA}$ were included in the results. Group 1 received artificial cerebrospinal fluid (aCSF) and Groups 2, 3, and 4 received methoxamine at 3 different doses $(0.5,1$, and $2 \mu \mathrm{mol}$ dissolved in aCSF). The aCSF was tested for pyrogens using the Limulus amoebocyte lysate (LAL) test (Blechova \& Pivodova, 2001). Bilateral injections $(0.2 \mu \mathrm{L})$ were given at a rate of $0.1 \mu \mathrm{L} / \mathrm{min}$, using an injector cannula made up of 30G stainless steel tubing. Each animal was given one bilateral injection. All injections were made at the same time $(12: 00 \mathrm{~h})$ to avoid the effect of circadian variation in the results. In Group 1 animals, S-W and $T_{b}$ were continuously recorded from 10:00 h to $15: 10 \mathrm{~h}, 2 \mathrm{~d}$ before the injection of aCSF (time control).

The S-W recordings were classified as active wakefulness $\left(\mathrm{W}_{1}\right)$, quiet wakefulness $\left(\mathrm{W}_{2}\right)$, light slow-wave sleep $\left(\mathrm{S}_{1}\right)$, deep slow-wave sleep $\left(\mathrm{S}_{2}\right)$, and REM, using the criteria mentioned in earlier reports (John et al., 1994). The recordings were divided into $15 \mathrm{sec}$ epochs and scored. The scored data were divided into bins of $15 \mathrm{~min}$ each, and the percentage of wake period in each $15 \mathrm{~min}$ bin was tabulated along with the corresponding $T_{b}$ values.

Preinjection data obtained from each group were analyzed by the non-parametric two-way analysis of variance (Friedman's test). Values of each bin of the aCSF group (Group 1) were compared with the identical bin of a time-control recording using the Mann-Whitney test. Finally, each bin of the aCSF group was compared with the identical bin of the drug administration groups (Groups 2, 3, 4) using the same test. Sleep latency was calculated by noting the time taken for the appearance of first 2 successive 15-sec epochs of sleep from the moment the animals were left in the chamber after they were handled for injection. At the end of the experiment, the brains of the animals were perfused with formaldehyde-saline as described in Bagga et al. (1981) for histological confirmation of drug-injection site.

\section{RESULTS}

The S-W and $T_{b}$ were recorded from 10:00 h to $15: 10 \mathrm{~h}$ in the Group 1 animals for obtaining control data. The rats spent $37.60 \pm 4.13$ percent of the time in wakefulness during the $5 \mathrm{~h}$ of recording. The duration of different components of S-W during the periods corresponding to preinjection and postinjection are shown in Table 1 . The mean $\mathrm{T}_{\mathrm{b}}$ of the animals was $37.27 \pm 0.49{ }^{\circ} \mathrm{C}$ at the beginning of recording at and $37.09 \pm 0.29^{\circ} \mathrm{C}$ at the end of recording.

The preinjection data of $T_{b}$ and wake period (W) obtained from different animals of each of the groups did not show any significant difference. The recorded values from the different groups were also comparable (Tables 1 and 2).

\section{Microinjection of aCSF:}

After the time control recordings, $0.2 \mu \mathrm{L}$ aCSF was injected in the mPOA of Group 1 animals. The mean $T_{b}$ during the preinjection period in this group of animals was $36.94 \pm 0.09^{\circ} \mathrm{C}$. Injection of pyrogen free aCSF caused an increase in $T_{b}$ (Fig. 2).By the end of the $3 \mathrm{~h}$, the mean $T_{b}$ of the animals was $38.61 \pm 0.55^{\circ} \mathrm{C}$. 


\section{TABLE 1}

Percentages of different sleep-wakefulness stages in different groups of rats before and after the injection of aCSF and methoxamine at the medial preoptic area, and recordings of the same parameters, 2 days before injection of aCSF, at identical timing. Sleep latency after the injection shown in last row.

\begin{tabular}{|c|c|c|c|c|c|c|}
\hline & & Time control & $\mathrm{aCSF}$ & & Methoxamine & \\
\hline & & & & $0.5 \mu \mathrm{mol}$ & $1 \mu \mathrm{mol}$ & $2 \mu \mathrm{mol}$ \\
\hline \multirow[t]{2}{*}{ W1 } & Preinjection & $19.38 \pm 12.65$ & $25.04 \pm 15.27$ & $36.13 \pm 20.04$ & $32.67 \pm 14.44$ & $33.96 \pm 15.97$ \\
\hline & Postinjection & $22.67 \pm 8.20$ & $22.86 \pm 2.46$ & $23.53 \pm 16.31$ & $30.78 \pm 13.8$ & $23.67 \pm 11.16$ \\
\hline \multirow{2}{*}{ W2 } & Preinjection & $14.71 \pm 4.54$ & $10.50 \pm 3.04$ & $9.33 \pm 2.98$ & $10.5 \pm 2.82$ & $14.71 \pm 3.84$ \\
\hline & Postinjection & $17.28 \pm 4.48$ & $12.39 \pm 1.89^{*}$ & $15.83 \pm 7.24$ & $13.33 \pm 8.28$ & $18.94 \pm 5.66$ \\
\hline \multirow{2}{*}{$\mathrm{S} 1$} & Preinjection & $44.67 \pm 6.28$ & $42.92 \pm 8.28$ & $40.08 \pm 13.89$ & $34.42 \pm 9.99$ & $36.67 \pm 10.64$ \\
\hline & Postinjection & $43.25 \pm 6.02$ & $46.56 \pm 3.45$ & $43.89 \pm 11.13$ & $36.94 \pm 16.35$ & $42.39 \pm 5.92$ \\
\hline \multirow{2}{*}{$\mathrm{S} 2$} & Preinjection & $11.58 \pm 3.02$ & $11.46 \pm 4.86$ & $9.04 \pm 4.4$ & $14.33 \pm 7.05$ & $9.96 \pm 5.08$ \\
\hline & Postinjection & $9.92 \pm 4.28$ & $14.06 \pm 1.72$ & $13.03 \pm 3.32$ & $14.44 \pm 4.68$ & $11.28 \pm 7.43$ \\
\hline \multirow{2}{*}{ REM } & Preinjection & $9.67 \pm 3.19$ & $10.58 \pm 4.45$ & $5.42 \pm 3.33$ & $8.83 \pm 2.13$ & $4.71 \pm 3.66$ \\
\hline & Postinjection & $6.94 \pm 1.77$ & $4.25 \pm 1.39$ & $3.72 \pm 2.45$ & $4.67 \pm 2.98$ & $3.72 \pm 2.12$ \\
\hline \multicolumn{2}{|c|}{ Sleep latency (min) } & & $10.05 \pm 5.56$ & $16.07 \pm 10.44$ & $17.60 \pm 23.28$ & $5.75 \pm 2.71$ \\
\hline
\end{tabular}

Data are expressed in mean \pm S.D. $(\mathrm{N}=5$ in each group $) ;{ }^{*} \mathrm{P}<0.05$ significance compared to time control recordings.

A comparison of individual bins showed that only one bin after 30 min showed a decrease in W, when compared with the corresponding bin of time control. A comparison of the different components of S-W (for $3 \mathrm{~h}$ ) after the aCSF injection, with their time control recordings, showed that these values were not significantly changed except for the $\mathrm{W}_{2}$, which was decreased (Table 1).

\section{Microinjection of methoxamine}

Microinjection of $0.5 \mu \mathrm{mol}$ (Group 2), $1 \mu \mathrm{mol}$ (Group 3), and $2 \mu \mathrm{mol}$ (Group 4) methoxamine induced a dose-dependent increase in the duration of hypothermia (Table 2). The fall in $\mathrm{T}_{\mathrm{b}}$ produced by 1 and $2 \mu \mathrm{mol}\left(1.28^{\circ} \mathrm{C}, 1.07^{\circ} \mathrm{C}\right)$ was higher than that produced by the $0.5 \mu \mathrm{mol}\left(0.41^{\circ} \mathrm{C}\right.$ ) injection (Fig 3). One bin after 120 min showed a decrease in $\mathrm{W}$ after methoxamine injection at all the three doses. An increase in $\mathrm{W}$ was produced in one bin (after $30 \mathrm{~min}$ ) after injection of methoxamine at doses of 1 and $2 \mu \mathrm{mol}$. This bin nearly coincided with the time of maximum fall in $T_{b}$. Comparison of drug induced changes in different stages of S-W for 3 hrs with aCSF readings showed that they were not significantly altered. Drug injection did not produce any change in the sleep latency also (Table 1). 
TABLE 2

Body temperature of rats before and after the injection of artificial cerebrospinal fluid (aCSF) and methoxamine at the medial preoptic area at three different doses.

\begin{tabular}{cccccc}
\hline & & \multicolumn{3}{c}{ Methoxamine } \\
\cline { 2 - 6 } Time & $0.2 \mu 1$ & $0.5 \mu \mathrm{mol}$ & $1 \mu \mathrm{mol}$ & $2 \mu \mathrm{mol}$ \\
\cline { 2 - 6 } PREINJECTION & $10: 00-12: 00$ & $36.94 \pm 0.09$ & $36.87 \pm 0.17$ & $36.97 \pm 0.16$ & $37.06 \pm 0.07$ \\
& & & & & \\
POSTINJECTION & $12: 10-12: 25$ & $37.45 \pm 0.30^{\dagger}$ & $36.89 \pm 0.31^{*}$ & $36.51 \pm 0.77$ & $36.57 \pm 0.42^{* *}$ \\
& $12: 25-12: 40$ & $37.51 \pm 0.09$ & $36.67 \pm 0.49^{* *}$ & $36.10 \pm 0.78^{* *}$ & $36.40 \pm 0.79^{* *}$ \\
& $12: 40-12: 55$ & $37.62 \pm 0.08^{\ddagger}$ & $36.46 \pm 0.53^{* *}$ & $35.75 \pm 0.84^{* *}$ & $36.14 \pm 1.08^{* *}$ \\
& $12: 55-13: 10$ & $37.65 \pm 0.11^{\ddagger}$ & $36.52 \pm 0.61^{*}$ & $35.69 \pm 0.76^{* *}$ & $35.99 \pm 0.92^{* *}$ \\
& $13: 10-13: 25$ & $37.78 \pm 0.47^{\dagger}$ & $36.71 \pm 0.69$ & $35.92 \pm 0.64 * *$ & $36.05 \pm 0.83^{* *}$ \\
& $13: 25-13: 40$ & $37.83 \pm 0.46^{\dagger}$ & $36.92 \pm 0.76$ & $36.26 \pm 0.65^{* *}$ & $36.14 \pm 0.75^{* *}$ \\
& $13: 40-13: 55$ & $37.99 \pm 0.63^{\dagger}$ & $37.22 \pm 0.83$ & $36.65 \pm 0.69^{*}$ & $36.30 \pm 0.78^{*}$ \\
& $13: 55-14: 10$ & $38.49 \pm 0.46^{\dagger}$ & $37.57 \pm 0.89$ & $37.16 \pm 0.92^{* *}$ & $36.41 \pm 0.95^{*}$ \\
& $14: 10-14: 25$ & $38.45 \pm 0.43^{\ddagger}$ & $37.93 \pm 0.81$ & $37.49 \pm 0.98^{*}$ & $36.61 \pm 0.99^{*}$ \\
$14: 25-14: 40$ & $38.37 \pm 0.28^{\ddagger}$ & $38.14 \pm 0.78$ & $37.75 \pm 1.07$ & $36.88 \pm 0.97$ \\
$14: 40-14: 55$ & $38.56 \pm 0.44^{\dagger}$ & $38.23 \pm 0.61$ & $37.86 \pm 0.98$ & $36.99 \pm 0.88^{*}$ \\
$14: 55-15: 10$ & $38.61 \pm 0.55^{\ddagger}$ & $38.48 \pm 0.58$ & $38.12 \pm 0.6$ & $37.16 \pm 0.91^{*}$ \\
\hline
\end{tabular}

Data are expressed in mean \pm S.D. $(\mathrm{N}=5$ in each group $)$

${ }^{*} \mathrm{P}<0.05,{ }^{* *} \mathrm{P}<0.01$ significance of methoxamine readings compared to aCSF. ${ }^{\dagger} \mathrm{P}<0.05,{ }^{\ddagger} \mathrm{P}<0.01$ significance of aCSF readings compared to time control.

\section{DISCUSSION}

The activation of $\alpha_{1}$ adrenoceptors of the mPOA induced a fall in $T_{b}$. The duration of this hypothermia was dose dependent. The drug injection did not produce any major shift in S-W or sleep latency.

\section{Medial Preoptic Injection of aCSF}

The hyperthermia observed after the injection of aCSF into the mPOA was similar to that seen in earlier reports (Romanovsky et al., 1993; Zhang et al., 1999). Insertion of an injector cannula at the mPOA has been reported to produce a rise in $T_{b}$ 


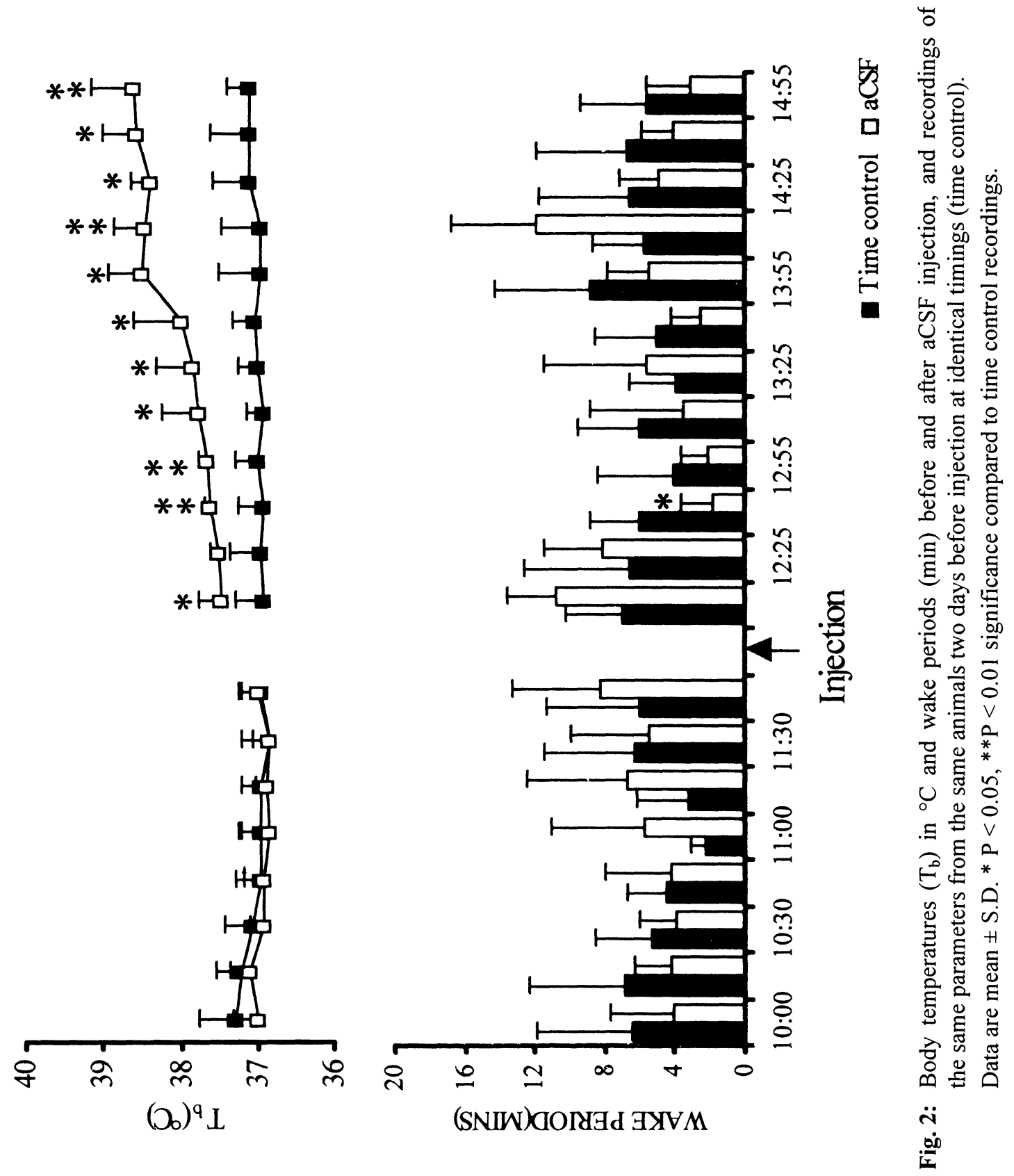




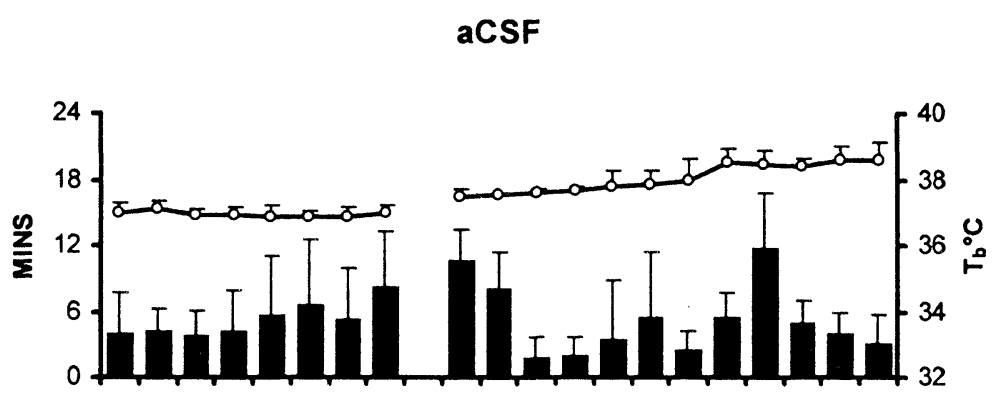

$0.5 \mu \mathrm{mol}$

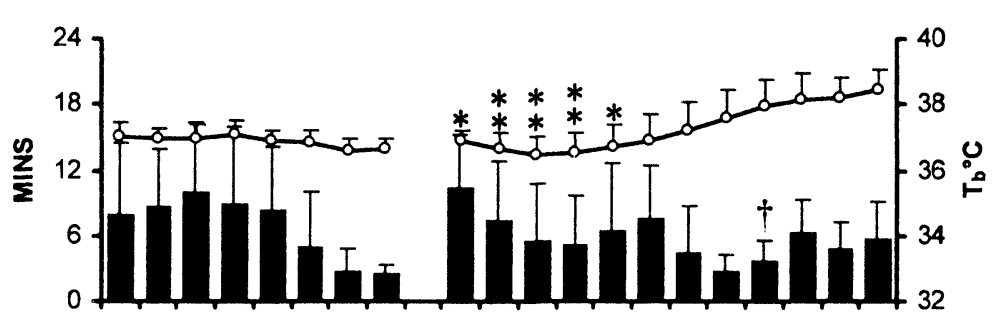

$1 \mu \mathrm{mol}$

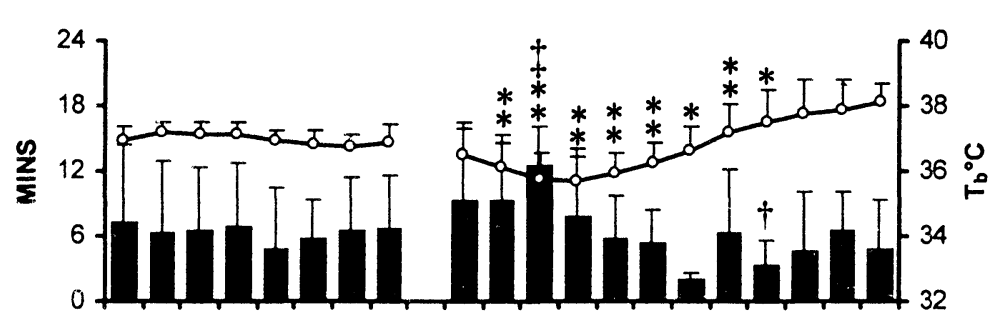

$2 \mu \mathrm{mol}$

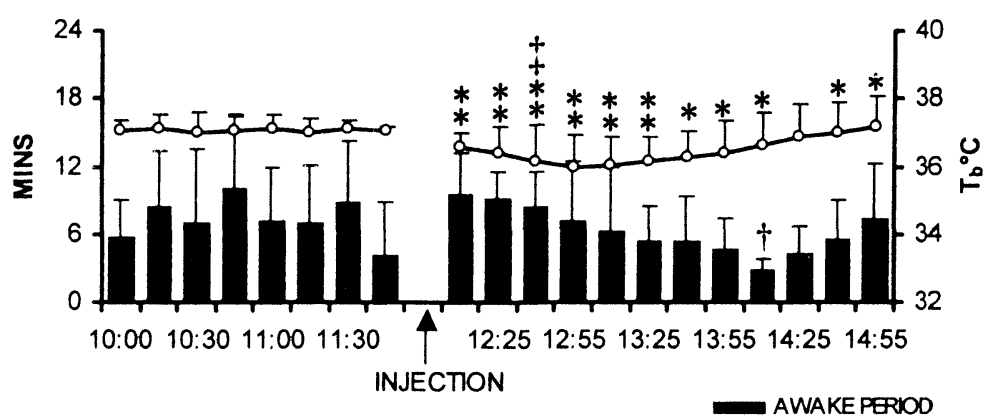

-

Fig. 3: Body temperatures $\left({ }^{\circ} \mathrm{C}\right)$ and wake periods (W) in 3 groups of rats after the injection of methoxamine at the medial preoptic area at doses $0.5,1$ and $2 \mu \mathrm{mol}$. Point of recording, at which drug was injected is shown by the arrow.

Data are mean \pm S.D. $* \mathrm{P}<.05,{ }^{* *} \mathrm{P}<0.01$ significance for $\mathrm{T}_{\mathrm{b}}$ compared to aCSF recordings. ${ }^{\dagger} \mathrm{P}<0.05$, ${ }^{\ddagger} \mathrm{P}<0.01$ significance for wake period compared to aCSF recordings. 
(Quan et al., 1988). As cytokines and prostaglandins are released in response to brain injuries (Rudy et al., 1977; Woodroofe et al., 1991), the rise in $T_{b}$ after injection of vehicle (aCSF) could be due to tissue injury and release of these mediators (Rudy et al., 1977; Walter et al., 1989). The increase in sleep seen in one bin after $30 \mathrm{~min}$ of aCSF injection might have been produced by cytokines and/or prostaglandins (Hayashi, 1988, Walter et al., 1989; Krueger and Takahashi, 1997).

\section{Medial preoptic injection of methoxamine on $T_{b}$}

The initial fall in $T_{b}$ produced by methoxamine injection into the mPOA in all the 3 doses tested is in line with earlier reports and further supports the idea that the $\alpha_{1}$ adrenergic receptors might mediate the hypothermic action of NE (Mallick \& Alam, 1992; Ramesh \& Kumar, 1998). As no significant difference was found in the fall in $T_{b}$ produced by 1 or $2 \mu \mathrm{mol}$ methoxamine, one could assume that the maximum fall in $T_{b}$ could be achieved by 1 $\mu \mathrm{mol}$ of the drug itself. But the duration of the fall in $T_{b}$ did show a dose-dependent increase. Although the mechanism of fall in $T_{b}$ was not investigated in this study, the fall in $T_{b}$ after NE injection was suggested to be due either to a nonevaporative heat loss (Poole \& Stephenson, 1979) or to a decrease in heat producing mechanisms (Mallick et al., 1988).

Phenylephrine, an $\alpha_{1}$ agonist, when microinjected into the POA, elicits hypothermia by suppressing shivering and peripheral vasodilation (Rudy \& Wolf, 1971). But methoxamine microdialyzed into the mPOA did not cause any change in skin temperature (Quan et al., 1992). Thus, the hypothermia induced by methoxamine might be due to a decrease in heat production. Also suggested is the possibility that NE afferents, which synapse on the temperature regulatory neurons, are activated when heat loss mechanism is to be initiated (Kumar, 2003a).

\section{Medial preoptic injection of methoxamine on S-W}

Although all the three doses of methoxamine produced prolonged hypothermia, they did not produce any major change in S-W. This result contradicts that of an earlier report (Mallick \& Alam, 1992), in which this drug was shown to increase $\mathrm{W}$. This discrepancy might be due to inadequacy of the technique, as continued presence of the rectal probe in the above mentioned study could have produced irritation and an increase in W. Moreover, a steep fall in $\mathrm{T}_{\mathrm{b}}$ could also increase W (Kent \& Satinoff, 1990). In this study also, W increased for one bin after 30 min of injection, which nearly coincided with the maximum fall in $T_{b}$. So, it is possible that the increase in $W$ resulted from a steep fall in $T_{b}$. Changes in S-W resulting from the administration of drugs into the POA need not be always dependent on the $\mathrm{T}_{\mathrm{b}}$ changes (Walter et al., 1989; Krueger \& Takahashi, 1997; Kumar, 1999). Lack of change in sleep latency after methoxamine injection in the present study supports the contention that stimulating the $\alpha_{1}$ adrenergic receptors of the mPOA does not produce any alteration in S-W. Moreover, a significant decrease in W occurred 30 min after the injection of aCSF. Drug injection readings at this time bin, when compared with aCSF readings, might show an increase when there is actually no change.

All three doses of methoxamine caused a significant increase in sleep for about $15 \mathrm{~min}$ $(120-135 \mathrm{~min})$. It is difficult to ignore this increase in sleep, which occurred in one bin in all groups. This increase could be a drug induced, long latency increase in sleep or a rebound sleep to compensate for the increased $\mathrm{W}$ observed a few minutes earlier. This increase in sleep observed for a period of one bin assumes significance in the light of other reports on the action of NE. Injection of NE into the mPOA, after the destruction of NE afferents, induces sleep (Kumar et al., 1993), 
although local injection of NE into the $\mathrm{mPOA}$ in normal rats induces arousal (Hernandez-Peon \& Chavez-Ibara, 1963; Datta et al., 1984; Kumar et al., 1993). After the destruction of NE fibers, locally injected NE can act only on postsynaptic receptors (Kumar et al., 1993). Postsynaptic NE receptors are mainly the $\alpha_{1}$ type (Langer, 1974). This finding led to the idea that $\alpha_{1}$ adrenergic receptors of the mPOA might have a hypnogenic role. Injection of the $\alpha_{2}$ agonist clonidine into the mPOA induces arousal and yohimbine, an $\alpha_{2}$ antagonist, induces sleep. The results of that study further support the contention that the normal postsynaptic action of NE at the level of mPOA would be to induce sleep and might be mediated through postsynaptic $\alpha_{1}$ adrenergic receptors. The arousal effect produced by the local application of NE might be due to its action on presynaptic $\alpha$ adrenergic receptors (Kumar et al., 1993; Ramesh et al., 1995). Also suggested is that different NE terminals bring about changes in sleep and $T_{b}$, which may be mediated through $\alpha_{1}$ adrenergic receptors. Moreover, the destruction of the noradrenergic afferents of the mPOA has been reported to cause an increase in W (Kumar et al., 1993).

We can conclude that the activation of $\alpha_{1}$ adrenergic receptors of the mPOA brought about a fall in $T_{b}$. Changes in S-W were viewed in the light of hypothermia, which occurred simultaneously. Although the results of the present study helped to dispel the notion about the involvement of $\alpha_{1}$ adrenergic receptors in arousal, they did not strongly support its role in hypnogenesis.

\section{ACKNOWLEDGEMENT}

This study was supported by Council of Scientific and Industrial Research.

\section{REFERENCES}

Anden NE, Dahlstrom A, Fuxe K, Olson L, Ungerstedt U. 1966. Ascending noradrenaline neurons from the pons and the medulla oblongata. Experientia 22: 44-45.

Andersson B, Gale CC, Hokfelt B, Larsson B. 1965. Acute and chronic effects of preoptic lesions. Acta Physiol Scand 65: 45-60.

Asala SA, Okano Y, Hondo K, Inoue S. 1990. Effects of medial preoptic area lesion on sleep and wakefulness in unrestrained rats. Neurosci Lett 114: 300-304.

Bagga N, Chhina GS, Kumar VM, Singh B. 1981. Mechanism of participation of medial preoptic area in the hippocampal inhibition of ovulation. Brain Res 216: 444-448.

Blechova R, Pivodova D. 2001. Limulus amoebocyte lysate (LAL) test-an alternative method for detection of bacterial endotoxins. Acta Vet Brno 70: 291-296.

Boulant JA. 1980. Hypothalamic control of thermoregulation: Neurophysiological Basis. In: Morgane PJ, Panksepp J, eds, Handbook of Hypothalamus, Vol. 3. New York, NY, USA: Marcel Dekker Inc; $1-82$.

Datta S, Kumar VM, Chhina GS, Singh B. 1987. Effect of application of serotonin in medial preoptic area on body temperature and sleepwakefulness. Ind J Exp Biol 25:681-685.

Datta S, Kumar VM, Chhina GS, Singh B. 1988. Interrelationship of thermal and sleep-wakefulness changes elicited from the medial preoptic area in rats. Exp Neurol 100: 40-50.

Datta S, Mohan Kumar V, Chhina GS, Singh B. 1985. Tonic activity of medial preoptic norepinephrine mechanism for body temperature maintenance in sleeping and awake rats. Brain Res Bull 15: 447451.

De Groot J. 1959. The rat forebrain in stereotaxic coordinates. Trans R Neth Acad Sci 52: 1-40.

Feldberg W, Myers RD. 1965. Changes in temperature produced by micro-injections of amines into the anterior hypothalamus of cats. J Physiol 177: 239-245.

Hayashi O. 1988. Sleep-wake regulation by prostaglandins D2 and E2. J Biol Chem 263: 14593-96. 
Hernendez-Peon R, Chavez-Ibarra CG. 1963. Sleep induced by electrical or chemical stimulation of the forebrain. Electroenceph Clin Neurophysiol 24: 188-198.

Hori T, Kiyohara T, Nakashima T, Shibata M. 1982. Responses of preoptic thermosenstitive neurons to medial forebrain bundle stimulation. Brain Res Bull 8: 667-675.

Hori T, Nakayama T. 1973. Effects of biogenic amines on central thermoresponsive neurons in the rabbit. J Physiol 232: 71-85.

John J, Kumar VM, Gopinath G, Ramesh V, Mallick HN. 1994. Changes in sleep-wakefulness after kainic acid lesion of the preoptic area in rats. Jap J Physiol 41: 1-22.

John J, Kumar VM. 1998. Effect of NMDA lesion of the medial preoptic neurons on sleep and other functions. Sleep 21: 585-595.

Kent S, Satinoff E. 1990. Influence of ambient temperature on sleep and body temperature after phentolamine in rats. Brain Res 511: 227-233.

Krueger JM, Takahashi S. 1997. Thermoregulation and sleep: closely linked but separable. Ann NY Acad Sci 813: 281-286.

Kumar VM, Khan NA. 1998. Role of the preoptic neurons in thermoregulation in rats. Arch Clin Exp Med 7: 24-27.

Kumar VM, Sharma R, Wadhwa S, Manchanda SK. 1993. Sleep inducing function of the noradrenergic fibres in the medial preoptic area. Brain Res Bull 32: 153-158.

Kumar VM. 2003a. Interrelation between thermoregulation and sleep regulation. Proc Indian Natl Sci Acad B69: 418-435.

Kumar VM. 2003b. Role of noradrenergic fibers of the preoptic area in regulating sleep. J Chem Neuroanat 26: 87-93.

Kumar VM. 1999. Role of preoptic area in the interrelationship between thermoregulatory and sleep regulatory mechanisms. Sleep Hypn 1: 1-9.

Langer SZ. 1974. Presynaptic regulation of catecholamine release. Biochem Pharmacol 23: 1793-1800.

Magoun HW, Harrison F, Brobeck JR, Ranson SW. 1938. Activation of heat loss mechanisms by local heating of the brain. J Neurophysiol 1: 101-114.

Mallick BN, Alam MN. 1992. Different types of norepinephrine receptors are involved in preoptic area mediated independent modulation of sleepwakefulness and body temperature. Brain Res 591: 8-19.
Mallick HN, Mohan Kumar V, Singh B. 1988. Thermal changes produced by norepinephrine application in the preoptic area of monkeys. Ind $\mathrm{J}$ Physiol Pharmacol 32: 265-270.

McGinty D, Sterman MB. 1968. Sleep suppression after basal forebrain lesions in the cat. Science 160: 1253-1255.

Mohan Kumar V, Datta S, Chhina GS, Gandhi N, Singh B. 1984. Sleep-wake responses elicited from the medial preoptic area on application of norepinephrine and phenoxybenzamine in free moving rats. Brain Res 322: 322-325.

Myers RD, Beleslin DB, Rezvani AH. 1987. Hypothermia: Role of $\alpha_{1}$ and $\alpha_{2}$ receptors in hypothalamus of cat. Pharmacol Biochem Behav 26: 373-379.

Nauta WJH. 1946. Hypothalamic regulation of sleep in rats: An experimental study. J Neurophysiol 9: 285-316.

Nicholas AP, Peiribone VA, Hokfelt T. 1993. Cellular localization of messenger RNA for beta-1 and beta- 2 adrenergic receptors in rat brain: an in situ hybridization study. Neuroscience 56: 1023-1039.

Osaka T, Matsumura H. 1995. Noradrenaline inhibits preoptic sleep-active neurons through $\alpha_{2}$ receptors in the rat. Neurosci Res 21: 323-330.

Osaka T, Matsumura H. 1994. Noradrenergic inputs to sleep-related neurons in the preoptic area from the locus coeruleus and ventrolateral medulla in the rat. Neurosci Res 19: 39-50.

Palacios JM, Wamsley JK. 1983. Microscopic localization of adrenoceptors. In: G.Kunos, ed, Adrenoceptors and Chatecholamine Action. Part B, New York, NY, USA: John Wiley; 295-313.

Palkovits M, Brownstein M, Saavendra JM, Axelrod J. 1974. Norepinephrine and dopamine content of hypothalamic nuclei of the rat. Brain Res 77 : 137-149.

Panskepp J, Jalowiec JE, Morgane PJ, Zolovick AJ, Stern WC. 1973. Noradrenergic pathways and sleep-waking states in cats. Exp Neurol 41: 233 245.

Poole S, Stephenson JD. 1979. Effects of noradrenaline and carbachol on temperature regulation of rats. Br J Pharmacol 65: 43-51.

Quan N, Van Huysse J, Howell RD, Ungar A, Blatteis CM. 1988. Hyperthermia evoked by intrapreoptic administration of pyrogen-free saline (PFS): abolition by microdialysis. FASEB J 2: A1531.

Quan N, Xin L, Ungar AL, Blatteis CM. 1992. Pre- 
optic norepinephrine-induced hypothermia is mediated by alpha- 2 adrenoceptors. Am J Physiol 262: R407-R411.

Ramesh V, Kumar VM. 1998. The role of alpha-2 receptors in the medial preoptic area in the regulation of sleep-wakefulness and body temperature. Neuroscience 85: 807-817.

Ramesh V, Kumar VM, John J Mallick HN. 1995. Medial preoptic alpha-2 receptors in the regulation of sleep-wakefulness. Physiol Behav 57: 171-175.

Ramesh V, Kumar VM. 2000. Changes in sleep-wakefulness after 6-hydroxy dopamine lesion of the preoptic area. Neuroscience 98: 549-553.

Romanovsky AA, Shido O, Ungar AL, Blatteis CM. 1993. Genesis of biphasic thermal response to intrapreoptically mincroinjected clonidine. Brain Res Bull 31: 509-513.

Rudy TA, Williams JA, Yaksh TL. 1977. Antagonism by indomethacin of neurogenic hyperthermia produced by unilateral puncture of the anterior hypothalamic/preoptic region. J Physiol (Lond) 272: 721-736.

Rudy TA, Wolf HH. 1971. The effect of intrahypothalamically injected sympathomimetic amines on temperature regulation in the cat. J Pharmacol Exp Ther 179: 218-235.

Scheinin M, Lomasney JW, Hayden-Hixson DM, Schambra UB, Caron MG, Lefkowitz RJ, et al. 1994. Distribution of $\alpha_{2}$ adrenergic receptor subtype gene expression in rat brain. Mol Brain Res 21: 133-149.

Sun JR, Ma YC, Xu ZH, Zhao WJ, Cai YP. 1997.
Effect of norepinephrine on the thermosensitive neurons in the preoptic area of hypothalamus tissue slices in cold acclimatized rats. $\mathrm{J}$ Physiol 49: 666-670.

Swanson LW, Hartman BK. 1975. The central adrenergic system: An immunofluorescence study of the location of cell bodies and their efferent connections in the rat utilizing dopamine- $\beta$ hydroxylase as a marker. J Comp Neurol 163: 467-506.

Ticho SR, Radulovacki M. 1991. Role of adenosine in sleep and temperature regulation in the preoptic area of rats. Pharmacol Biochem Behav 40: 33-40.

Unnerstall JR, Kopajtic TA, Kuhar MJ. 1984. Distribution of $\alpha_{2}$ agonist binding sites in the rat and human central nervous system; analysis of some functional, anatomic correlates of the pharmacologic effects of clonidine and related adrenergic agents. Brain Res Rev 7: 69-101.

Walter JS, Meyers P, Krueger JM. 1989. Microinjection of interleukin-1 into brain: separation of sleep and fever responses. Physiol Behav 45: 169-176.

Woodroofe MN, Sarna GS, Wadhwa M, Hayes GM, Loughlin AJ, Tinker A, et al. 1991. Detection of interleukin- 1 and interleukin- 6 in adult rat brain, following mechanical injury, by in vivo microdialysis: evidence for a role for microglia in cytokine production. J Neuroimmunol 33: 227-236.

Zhang J, Ferenc Obal Jr, Zheng T, Fang J, Taishi P, Krueger JM. 1999. Intrapreoptic microinjection of GHRH or its antagonist alters sleep in rats. J Neurosci 19: 2187-2194. 

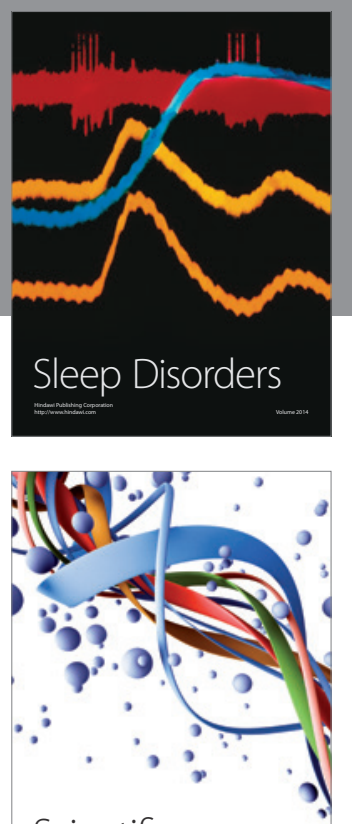

Scientifica
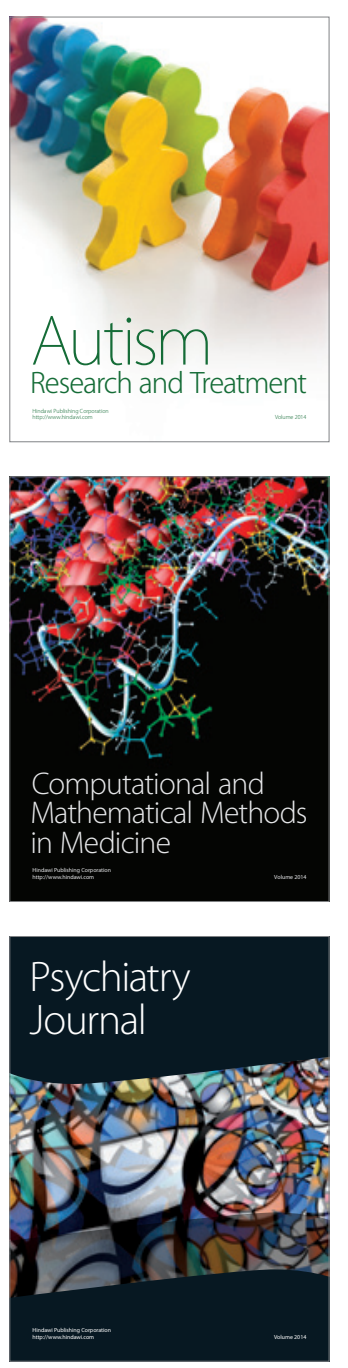
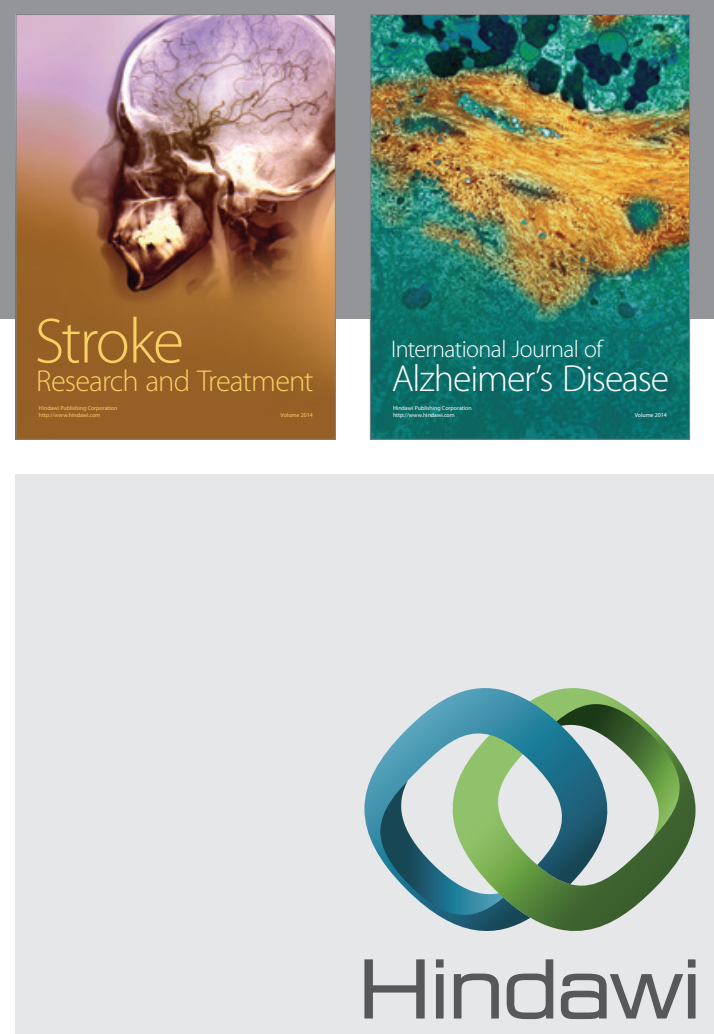

Submit your manuscripts at

http://www.hindawi.com
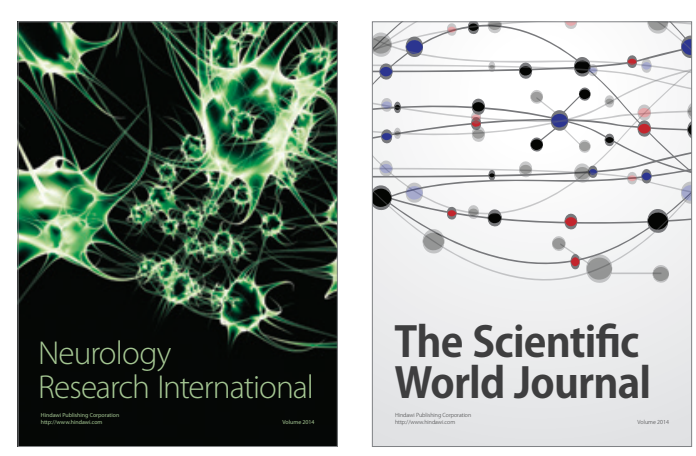

The Scientific World Journal

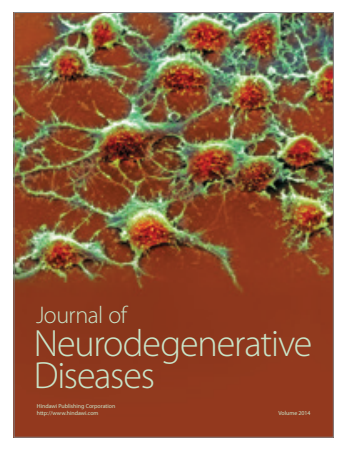

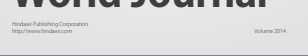

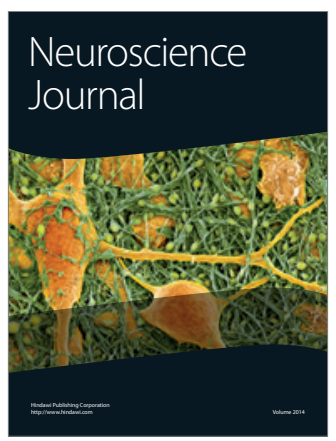

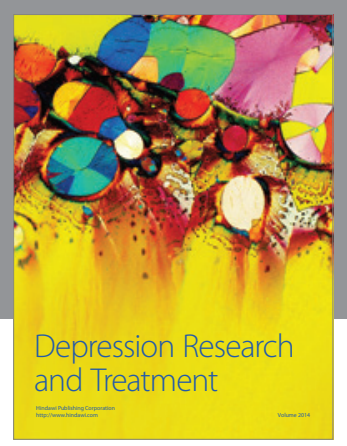
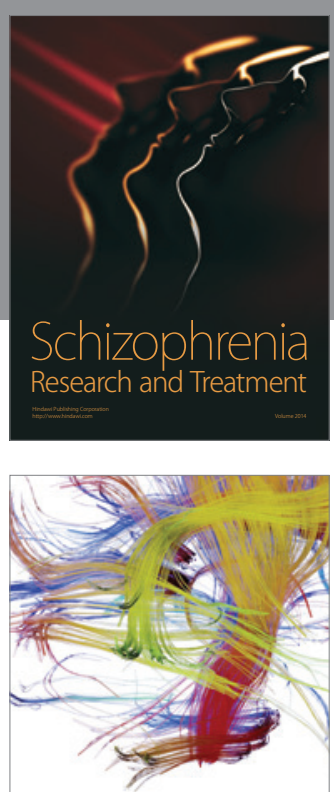

Brain Science

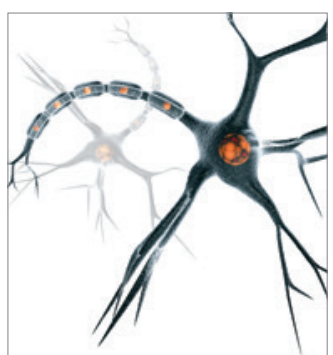

Neural Plasticity
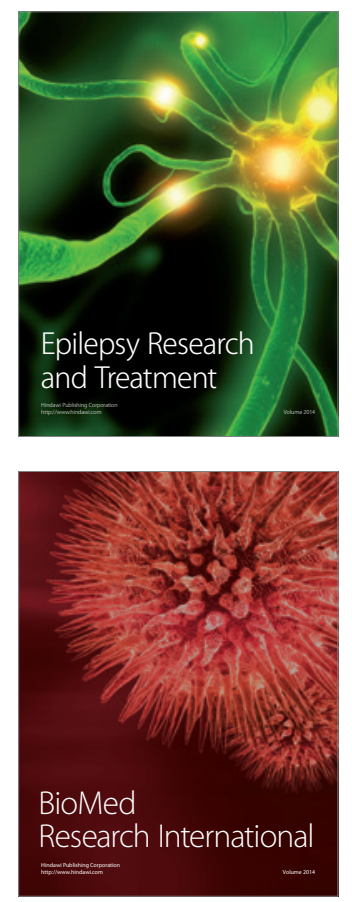

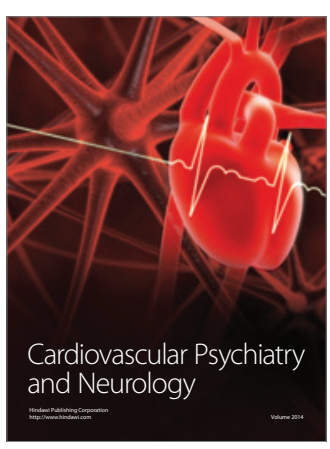

Parkinson's

Disease
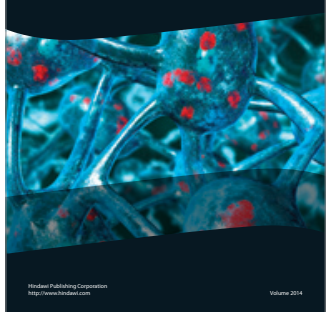